\title{
Tracheal Compression Associated with Esophageal Achalasia
}

\author{
Mio Kurimoto, Nobuo Sakata and Takeshige Kunieda
}

Key words: achalasia, tracheal compression

(Intern Med 53: 2753-2754, 2014)

(DOI: 10.2169/internalmedicine.53.3238)
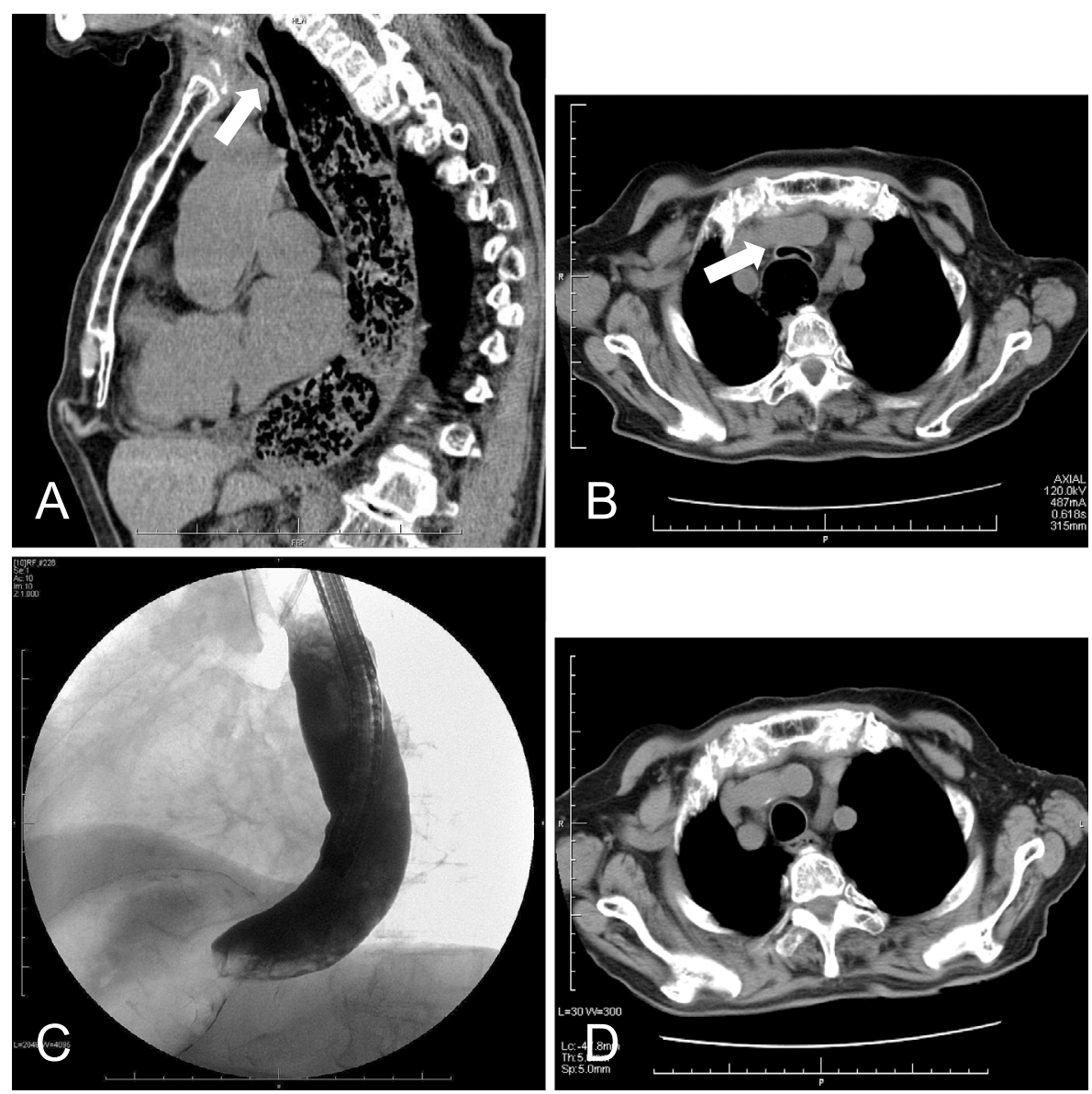

Picture.

An 88-year-old woman presented to the emergency department with a severe cough without dysphagia. She was otherwise asymptomatic until the morning of her visit. A physical examination revealed expiratory stridor. Computed tomography (CT) showed a dilated esophagus filled with a large amount of food residue compressing the trachea (Pic- ture A, B, arrows). Immediately after CT, likely as a result of lying down, the patient's nausea and vomiting worsened, which exacerbated her dyspnea. Therefore, she was intubated and admitted to the medical intensive care unit. Upper endoscopy confirmed marked esophageal dilatation and the presence of abundant food residue, and esophagography re- 
vealed esophageal achalasia (Picture C). Repeated endoscopic balloon dilatation to treat the achalasia showed tracheal compression (Picture D). On day 3 after admission, the patient was extubated and was thereafter able to maintain a sufficient oral intake. Although the symptoms of achalasia can usually be controlled with treatment, unexpected deaths may result from unsuspected achalasia (1).
The authors state that they have no Conflict of Interest (COI).

\section{Reference}

1. Schalinski S, Guddat SS, Tsokos M, Byard RW. Megaesophagus and possible mechanisms of sudden death. J Forensic Sci 54: 216219, 2009.

\footnotetext{
(C) 2014 The Japanese Society of Internal Medicine http://www.naika.or.jp/imonline/index.html
} 